\title{
Mendelssohn, Kant, and the Mereotopology of ImMORTALity
}

\author{
JONATHAN SIMON \\ New York University \\ COLIN MARSHALL \\ University of Washington
}

In the first Critique, Kant claims to refute Moses Mendelssohn's argument for the immortality of the soul. But some commentators, following Bennett (1974), have identified an apparent problem in the exchange: Mendelssohn appears to have overlooked the possibility that the "leap" between existence and non-existence might be a boundary or limit point in a continuous series, and Kant appears not to have exploited the lacuna, but to have instead offered an irrelevant criticism. Here, we argue that even if these commentators are correct, an argument against the leap-as-limit possibility is implicit in claims that Mendelssohn accepts. Moreover, Kant's criticism of Mendelssohn adapts naturally into a response to this argument, though Mendelssohn endorses further claims which enable him to address this Kantian response. To illustrate the philosophical issues in play, we conclude by noting the affinity between the Mendelssohnian argument we develop and several prominent arguments in contemporary metaphysics: David Lewis's argument from vagueness for unrestricted composition, Ted Sider's argument from vagueness for perdurantism, and Peter Unger's argument from the problem of the many for substance dualism. In short, we argue that the philosophical issues involved in the Mendelssohn-Kant exchange are much richer than previous commentators have believed, and that there is a Mendelssohnian argument for the immortality of the soul (or anyway, the permanence of simples) that does not suffer from any obvious flaw.

$\mathrm{I}$

$\mathrm{N}$ his Phädon, Moses Mendelssohn defends the immortality of the soul by adapting the arguments in Plato's Phaedo "to the taste of our time,"1 and by

1. Mendelssohn (2007: 42).

Contact: Jonathan Simon < jas741@nyu.edu> and Colin Marshall <crmarsh@uw.edu> 
putting additional arguments in Socrates' mouth. ${ }^{2}$ In the second edition of the Critique of Pure Reason, Kant claims to refute one of Mendelssohn's main arguments from the Phädon. According to Kant, this argument runs as follows:

a simple being cannot cease to be at all because, since it cannot be diminished and thus lose more and more of its existence, and so be gradually transformed into nothing (since it has no parts and thus no plurality in itself), there would be no time at all between a moment in which it is and another moment in which it is not, which is impossible. $\left(B_{413}-14\right)^{3}$

According to Kant, this argument fails because it overlooks the possibility that a simple being "could be transformed into nothing ... by a gradual remission of all its powers (hence ... through elanguescence)" (B414). Many of Kant's commentators seem to believe that Kant's objection is decisive, while the commentators who seriously consider the philosophical merits of Mendelssohn's argument tend to suppose that Kant missed Mendelssohn's point. ${ }^{4}$

We hold that this exchange is philosophically richer than others have suggested. We will argue that there is a construal of the debate according to which both Mendelssohn's argument and Kant's objection have significant philosophical merit. We will then suggest that Mendelssohn nevertheless has the materials to respond to Kant, amounting to an argument for the immortality of the soul (or anyway, the permanence of simples - a qualification to be explained just below) without any obvious flaws. To help illustrate the merit of this argument, we will conclude by considering the affinity between the Mendelssohnian argument and

2. The main argument in the second dialogue of the Phädon develops the traditional argument which Kant calls "the Achilles of Rationalist Psychology." See Mijuskovic (1974).

3. All references to the Critique will use standard A/B citations, while references to other works by Kant will give volume and page numbers for the Academy edition of Kant's works. Kant gives a more minimal (and less charitable) summary of Mendelssohn's argument elsewhere (see, e.g., Metaphysics Mrongovius 29: 905, 912; Metaphysical Foundations of Natural Science 4:542-43). Wuerth (2014: 153-55, 181) provides a list of precedents.

4. Many commentators who discuss the argument seem to simply grant that Kant's objection succeeds. See Ameriks (2000: 184), Klemme (1996: 366-370), and Wuerth (2014: 180-181). Kant's criticism of Mendelssohn is ignored in otherwise thorough discussions of Kant's views on the soul such as Allison (2004), Brook (1997), Dyck (2014), Grier (2001), Kitcher (2011) (several of which note other aspects of Kant's relation to Mendelssohn). Bennett (1974) and Powell (1990) (discussed below) offer more detailed discussions of the issues, though both seem to think Kant's response is sufficient to defuse the argument. By contrast, Strauss (1972: xxvi-xxvii) and Falkenstein (1998) (whose focus is the suggestion that there is tension between Kant's response and Kant's theory of matter) criticize Kant for overlooking relevant passages in Mendelssohn's Phädon (Falkenstein 1998: 586-588) in which Mendelssohn appears to consider and reply to the sort of objection Kant has in mind-a problem further detailed in Sassen (2008: 220) and Tomasoni (2011: 133). We discuss this issue at length below. 
prominent contemporary arguments. We note that, while we aim to show that the arguments we develop follow from claims that Mendelssohn and Kant endorse, our primary aim is not to establish that Mendelssohn or Kant actually had these arguments in mind. But we note several advantages of this interpretive hypothesis along the way.

\section{The Puzzling Exchange}

Mendelssohn's Phädon is a series of three dialogues presenting a master argument for the immortality of the soul. The portion of this master argument of interest to us occurs in the latter half of the first dialogue (Mendelssohn 2007: 88-101). As Mendelssohn (2007: 150) glosses this portion of the master argument in the appendix to the third edition, it assumes that souls are simples and goes on to argue that they can disappear neither gradually nor suddenly, and hence must be immune to destruction by natural forces. ${ }^{5}$ Later in the text, Mendelssohn argues that the soul is simple, and that after the death (and decomposition) of the body the soul not only continues to exist but retains its rational powers, and indeed continually develops them (and hence is not merely permanent, but immortal). But in this paper we will restrict our attention to the argument for the permanence of simples. This is the argument that Kant summarizes at B413-414, and this is the argument he means to refute.

In our view, Kant's presentation of Mendelssohn's argument is accurate, though condensed in a potentially misleading way. ${ }^{6}$ Following Kant, the argument can be recast as follows:

1. Since it lacks parts, a simple being cannot be gradually transformed into nothing.7

2. If something cannot be gradually transformed into nothing, then it can

5. See Dyck (2014) for a helpful general discussion of pre-Kantian arguments for the simplicity of the soul, and Falkenstein (1998: 566) for some background on Mendelssohn's arguments for simplicity in the Phädon. Kant apparently also takes Mendelssohn to deny the soul has any spatial extent. Today, some countenance the possibility of spatially extended simples (e.g., Markosian 1998; cf. Van Cleve 1999: 66). As we will explain in Footnote 13 below, this yields an alternative to Kant's reply, but one that ultimately fares no better.

6. Kant's presentation is misleading because it suggests that what we here identify as premises one and two were indeed premises for Mendelssohn rather than intermediate conclusions. What defenses Mendelssohn did or could have offered for these premises will be the main focus of this paper.

7. Cf. Mendelssohn (2007: 93): “The decay [of a composite] increases gradually by imperceptible degrees. Finally the structure falls to pieces, and dissolves into its smallest parts. But what happens? Do these parts cease to undergo changes? Are they entirely lost? . . Impossible!" 
cease to be only if it has a last moment of existence and a distinct first moment of non-existence. ${ }^{8}$

3. Therefore, a simple being can cease to be only if it has a last moment of existence and a distinct first moment of non-existence. $(1,2)$

4. If something had a last moment of existence and a distinct first moment of non-existence, then there would be two distinct moments with no intermediate moment. 9

5. Since time is continuous, there are no two distinct moments with no intermediate moment. ${ }^{10}$

6. Therefore, no simple being has a last moment of existence and a distinct first moment of non-existence. $(4,5)$

7. Therefore, no simple being can cease to be. $(3,6)^{11}$

Since the argument so presented is valid, a successful objection must undermine one of the assumptions, that is, step one, step two, step four, or step five.

Kant claims that the argument fails because a simple being could cease to be through elanguescence, that is, through the gradual extinction of its powers. This reply assumes that a simple being requires powers to exist, but Mendelssohn

8. Cf. Mendelssohn (2007: 93): “Therefore being and not-being would be two states which immediately follow on one another, which must be closest to each other." The 'therefore' refers to the reasoning reproduced in Footnote 7 just above.

9. Cf. Mendelssohn (2007: 93). Neither Mendelssohn nor Kant make this step explicit. This step requires that the existence of a simple being cannot be vague-otherwise, there could be a last moment of existence, a first moment of non-existence, and in between these, intermediate moments at which it is indeterminate whether or not the thing exists. But neither Mendelssohn nor Kant endorse the possibility that simple beings' existence might be vague, as we argue in greater detail below. Elanguescence does not entail vagueness unless things can possess some positive degree of being without determinately existing. Otherwise, there is a sharp cut-off between having no being at all, and having any being at all (as Mendelssohn stresses at 2007: 98). This makes the argument under consideration here an intellectual ancestor of Lewis's (1986) argument for unrestricted composition and Sider's (2001) argument for perdurantism. We revisit this theme in Section 5 .

10. Cf. Mendelssohn (2007: 92): "The succession of time proceeds in a continuum, and there are no two moments, which are closest to one another."

11. Powell (1990: 113) rightly points out that this conclusion is not sufficient for the immortality of the soul, if a simple being might cease to be a soul and become something else. As we note, Mendelssohn is aware of this concern (first acknowledging it at 2007: 97-98, in remarks reproduced just below) and he devotes much of the second and third dialogues to it. Again, our focus here is on the argument for the permanence of simples, which would be significant even if Mendelssohn's further conclusions did not follow. Note, though, that Kant might recast his challenge in such a way as to cede the permanence of simples, by arguing that a simple being ceases to be a soul when it loses all cognitive faculties, and that this can happen gradually, without the simple ceasing to be (cf. Sassen 2008: 221). We will see below why this does not substantively advance the dialectic. In Section 5 below, we note that the Mendelssohnian argument may also be deployed concerning anything having the property of being phenomenally conscious, regardless of whether it is substantially simple. 
grants this assumption: "Shall all its sensations, its imaginations, its desires and aversions, appetites and passions vanish, and leave behind not the slightest trace? Impossible. ... What would this be other than a total annihilation [?]" (Mendelssohn 2007: 97-98). Moreover the view was widely shared at the time, ${ }^{12}$ and (provided 'powers' is understood broadly, to include all causally efficacious qualities) it remains plausible today. As we will discuss below, however, there are important questions here concerning the exact relation of a soul to its powers.

That aside, which step of the argument does Kant take elanguescence to defeat? On the face of things, his target seems to be premise one. Kant's suggestion seems to be that if a process of remission (i.e., diminution) of powers that culminates in a disappearance can be gradual, then so can be the disappearance itself. ${ }^{13}$

But Mendelssohn explicitly addresses the metaphysical possibility Kant describes, arguing that going out of being through a loss of powers still involves a "leap" from being to nothingness: "for the final step, one may postpone it as long as possible, would still always be a leap from being to nothingness, which neither can be established in the nature of a discrete thing, nor in the continuum" (2007: 98). ${ }^{14}$ Mendelssohn thus appears to consider and reject the hypothesis that disappearance by elanguescence is "gradual" in the sense relevant to premise one, while Kant appears to write as though the possibility of elanguescence had not occurred to Mendelssohn. Accordingly, insofar as Kant's challenge is aimed at premise one, it fails to engage appropriately with its target. ${ }^{15}$

Meanwhile, some commentators have suggested that premise two is clearly faulty. Jonathan Bennett, for example, claims that:

Mendelssohn's argument fails, because it is based on a wrong view about what non-gradual or discontinuous change would have to involve. An item $x$ can change discontinuously from being $F$ to being $G$ just so long as there is an instant $t$ such that $F x$ at $t$ and $G x$ at every instant after $t$. There is no question of $x$ 's being $G$ at the 'next instant': there is no 'next

12. "monads must have some qualities, otherwise they would not even be beings" (Leibniz 1989: 40-41, Monadology Section 8).

13. As mentioned above, some hold that simples may occupy extended spatial regions. If so, it might be the case that a simple gradually gets smaller on its way to non-existence. This gradual diminution would involve only extensive magnitudes.

14. Is Mendelssohn here indicating that there are two distinct sets of considerations in play, one that holds for "discrete" things, the other holding for "continuous" ones? A look at the original text suggests otherwise: "der weder in dem Wesen eines einzelnen Dinges, noch in dem ganzen Zusammenhange gegruendet seyn kann" (Mendelsohn 1972: 73). The claim seems to be that the capacity for this kind of leap neither stems from the nature of the individual thing in question, nor from the nature of reality as a whole. This leaves open whether Mendelssohn accepts that, if time were discrete, qualitative leaps (from one moment to the next) would be possible.

15. Strauss (1972: xxvi-xxvii), Falkenstein (1998: 588), Sassen (2008: 220) and Tomasoni (2011: 133) all discuss this apparent failure of Kant's to note Mendelssohn's reply to his objection. 
instant', for the set of instants-later-than- $t$ has no earliest member. $(1974: 58)^{16}$

In effect, Bennett claims that Mendelssohn is confused about the nature of "non-gradual or discontinuous change." In particular, if Bennett is correct, then Mendelssohn is not offering an argument against the possibility of non-gradual or discontinuous change, but rather, Mendelssohn just fails to consider the possibility that a discontinuous function can describe a process that unfolds in (continuous) time. But this would be a glaring omission on Mendelssohn's part, and also, by extension, a failure on Kant's, since such a glaring omission would be a more vulnerable target than Kant's chosen target (premise one), or would at least be worthy of mention. ${ }^{17}$ For if Mendelssohn were not offering an argument against the possibility of non-gradual or discontinuous change unfolding in continuous time, someone could hold that there is a boundary point or limit in time between the soul's existence and non-existence (rather than a last moment of existence followed immediately by a first moment of non-existence) without bothering about elanguescence at all, or while maintaining that the soul loses power by discrete steps and retains some quantity of power up to the limit point of its existence. ${ }^{18}$

Crucially, while it would be anachronistic to insist that Mendelssohn or Kant anticipated advances in calculus grounded in the delta/epsilon conception of a limit, ${ }^{19}$ nothing as sophisticated as that is called for here. It is no anachronism to suppose that both would be familiar with the notion of a boundary in a continuum, or a continuous process: for example, in the spatial case, a line dividing a plane, or in the temporal case, for the arrow to be located at some specific location at noon, but not before. ${ }^{20}$ In particular, a close reader of Leibniz would be familiar with these notions, ${ }^{21}$ and Mendelssohn's familiarity with Leibniz (and

16. For another suggestion that Mendelssohn fails to support premise two, see Powell (1990: 113-116).

17. Sassen (2008: 220) endorses Bennett's suggestion that both Mendelssohn and Kant overlook the relevant possibility.

18. Though see Powell (1990: 116) for a discussion of why Kant might have been inclined not to proceed in this manner.

19. A point made by Falkenstein (1998: 588). But see Cajori (1923) for evidence that prototypes of the relevant tools were already in development by the time of Mendelssohn's writing.

20. We return to the more vexed question of the motion of the arrow below. For a detailed history of conceptions of continuity see Bell (2013).

21. Consider for example the preface to the New Essays, in the very passage where Leibniz introduces the principle of continuity (Natura saltus non facet):

Nothing takes place suddenly, and it is one of my great and best-confirmed maxims that nature never makes a leap. I call this the law of continuity ... It implies that any change from large to small, or vice versa, passes through something which is, in respect of degrees as well as of parts, in be- 
later mathematicians) is clear. ${ }^{22}$

Moreover, in the Phädon, Mendelssohn himself makes clear that a point in the midst of a continuum is a boundary between the preceding and succeeding points. Considering the process by which the "animal machine" dissolves, he says "in such a continuous process, ... every state can be called a boundary condition of the previous and following states" (Mendelssohn 2007: 96).

Kant, for his part, sees moments of time as limits:

Points and instants are only boundaries, i.e., mere places of their limitation; but places always presuppose those intuitions that limit or determine them, and from mere places, as components that could be given prior to space or time, neither space nor time can be composed. (A169-170/ B211)

So Mendelssohn and Kant both seem to have the concept of a boundary point. The question is whether both simply fail to consider the (mathematical) possibility of a qualitatively discontinuous "leap" occurring at a boundary point in continuous time (rather than between adjacent moments in discrete time), even though both had the concepts to understand this possibility.

In our view, this allegation relies on an uncharitable reading of Mendelssohn. Mendelssohn has an argument that discontinuous functions defined on continuous parameters (like time) cannot describe the operation of nature. This argument relies on the principle of continuity, which Mendelssohn explicitly endorses: "nature in all its changes knows to find an intermediate state, which serves as a transition, likewise, to go from one state to the opposite" (2007: 88). ${ }^{23}$

tween; and that no motion ever springs immediately from a state of rest, or passes into one, except through a lesser state of motion; just as one could never traverse a certain line without first traversing a shorter one. (Leibniz 1996: 56)

Crucially, here, Leibniz acknowledges that a thing in motion can come to rest through a continuous process, provided that every intermediate value is attained. Or consider this discussion of boundaries:

a common boundary of two things is an entity which is in them when they do not have a part in common. Insofar as these two things are understood to be parts of a single whole, their common boundary is called the section of the whole. It is clear from this that a boundary is not homogenous with what it bounds, ... [but] nevertheless homogonous, because one can disappear into the other by a process of continuous change. (Leibniz 1969: 666-668, translating Leibniz 1963: VII, 17ff.)

22. See Shavin (1999; 2007). As Shavin notes (1999: Section 2; 2007: 9-10), Mendelssohn and Lessing's work "Pope, A Metaphysician" includes a reference to a letter of Leibniz's disproving some of Maupertius's allegations concerning the origins of the principle of least action (Cf. Kabitz 1913). Mendelssohn's 1763 prize essay, "On Evidence in the Mathematical Sciences" discussed the methodology of calculus and geometry in comparison with that of philosophy.

23. A natural operation ... must have a beginning, a middle, and an end, that is to say, some time must elapse, before it is completed ... an effect, which cannot be prepared in advance, which 
So construed, the principle of continuity rules out a natural process of change that can be represented by a discontinuous function defined over a continuous time parameter. ${ }^{24}$

A natural operation ... must have a beginning, a middle, and an end, that is to say, some time must elapse, before it is completed ... an effect, which cannot be prepared in advance, which must occur in an instant, ceases to be natural, and cannot be produced from powers which must do everything in time. (Mendelssohn 2007: 150)

But this does not fully answer Bennett, and a puzzle remains. For in Mendelssohn's discussion of elanguescence (2007: 97-98) leading up to the conclusion about the "leap from being to nothingness," he appears to allow that the diminution of a soul's power to zero might be continuous. His objection is that such a process must involve a specific final moment (a "leap" from being to nothingness), not that it must skip over some intermediate values (of power).

But then the principle of continuity does not obviously tell against disappearance by elanguescence. Such a process may well involve a specific final moment, and this may be enough to make the process "non-gradual" in Mendelssohn's sense. But on its face this is no more a violation of continuity than is an arrow's going from a state of motion to a state of rest.

If this is correct, Kant's appeal to elanguescence does not miss the mark after all, and properly construed it targets premise two, not premise one. Disappearance by elanguescence may well be "non-gradual" in Mendelssohn's sense-it has a specific final moment-but it is nevertheless continuous, and so it is immune to Mendelssohn's argument from the principle of continuity. Mendelssohn must produce further arguments against the possibility that the soul may continuously (but "non-gradually") disappear by elanguescence.

This reading may acquit Kant of the charge of negligence, but it does not acquit Mendelssohn, and so an interpretive puzzle remains. Given his concern with continuity, Mendelssohn arguably should have been able to see that his

must occur in an instant, ceases to be natural, and cannot be produced from powers which must do everything in time. (Mendelssohn 2007: 150)

He also states that the principles at the core of his argument are "reasonably clear to common sense; but, in my opinion, they obtain a high degree of certainty only through the doctrine of continuity" (Mendelssohn 2007: 151; cf. Leibniz 1996: 56).

24. Arguably, this does not directly rule out a discontinuous change defined over a discrete time parameter: a change involving a last moment before the change and a first moment after, with no moments in between. If so the appeal to the principle of continuity explains the form of premise two. Note that this is neutral on whether the continuity of time is an independent premise (as the wording of Mendelssohn's text on page 92 suggests), or on whether it ultimately follows from the principle of continuity, as Mendelssohn elsewhere seems to imply (e.g., 2007: 150). 
argument required further support at this crucial juncture. We turn now to the case that Mendelssohn had the materials to support his argument accordingly.

\section{Boundaries and Sufficient Reason}

Following Leibniz, Mendelssohn endorses the Principle of Sufficient Reason (PSR), which rules out any fact being wholly arbitrary. ${ }^{25}$ Indeed, Mendelssohn makes use of the principle to offer a quick, supporting argument for his conclusion that sudden disappearance or annihilation is impossible. "Assume it were not impossible," Socrates instructs Cebes. But because the body dies gradually, by decomposing, Socrates reasons, "there is no definite moment, where one can say, now the animal dies ... therefore, if the death of the body is also supposed to be the death of the soul: there must be no moment at which one can say, now the soul vanishes" (Mendelssohn 2007: 96). For the soul to disappear at any given moment in the process would be arbitrary, since that moment no more corresponds to the true moment of death of the body than do other, nearby moments. Mendelssohn has Socrates conclude that the soul cannot go out of being in a single instant, against the assumption for reductio. Below, we will refer to this as Mendelssohn's Arbitrary Timing Argument.

Now, the Arbitrary Timing Argument is not likely to persuade the unconvinced. In particular, if we are granting that there can be well-defined processes of elanguescence with precisely defined boundary points, then we should expect that whatever dynamics governs these processes, together with whatever explains why they begin where they do, will also explain why they terminate where they do.

But this argument was intended to be only a supporting argument, a further consideration worth mentioning after Socrates has already established the impossibility of sudden annihilation. Socrates must ask Cebes to assume annihilation were not impossible, because he has already argued that it is. So the question remains, is there a more compelling argument available to Mendelssohn for the impossibility of sudden annihilation?

Our suggestion is that there is such a more compelling argument, one which also relies on considerations of arbitrariness, and which also could account for Mendelssohn's concern with last moments of existence and first moments of

25. See again Shavin (2007) for general discussion of the influence of Leibniz on Mendelssohn. See also Strauss (1972: xii-xxxviii). Mendelssohn explicitly endorses the PSR, for example, here:

each determination presupposes a condition of the determinable subject, on the basis of which it can be comprehended why it is determined in one way rather than another ... it can be comprehended how, by virtue of a certain condition of the subject, it is settled whether the predicate is part of the subject or not. (1997: 284) 
non-existence. We will call this the Arbitrary Mereotopology Argument. This Mendelssohnian argument for permanence, moreover, lacks any obvious flaws. Mendelssohn never explicitly formulates the Arbitrary Mereotopology Argument, but nothing rules out that he has it in mind: its premises follow from claims that he accepts, sheds light on other claims he makes, and it addresses what would otherwise seem to be a loophole in his defense of premise two via the principle of continuity.

Recall again that in the loophole case in question, a simple being's existence is bounded by a single point of time, so that it exists at all previous times and does not exist at any later times. The question then arises, does the simple exist at this boundary point itself? It cannot be a moment at which the simple neither exists nor fails to exist, and it also cannot be a moment at which the simple both exists and fails to exist. ${ }^{26}$ So which is it: does the simple have a last moment of existence, or a first moment of non-existence? The worry is that either answer would be arbitrary. ${ }^{27}$ Notably, this arbitrariness arises even if we suppose that, contra the Arbitrary Timing Argument, somehow the exact timing of the soul's terminal boundary point is non-arbitrary.

There are many reasons to resist theories that imply this kind of arbitrariness, and in the contemporary literature (as we will discuss below) many metaphysicians do so who, unlike Mendelssohn, do not endorse the general Principle of Sufficient Reason. But the principle appealed to here is a relatively modest implication of the general PSR, and so, accordingly, we call it

The Principle of Mereotopological Sufficient Reason (PMSR): Where there are determinate facts of the matter about whether a thing contains its boundary points, these facts are rationally explicable.

Here is the argument ruling out the loophole case (the Arbitrary Mereotopology Argument), cast in terms of the PMSR: If there is a single boundary point between the period of time during which the soul exists and the period during

26. We might think of these as cases in which it is vague whether the simple exists. But here this vagueness would have to be ontological, or involve quantifier variance, prospects that a rationalist like Mendelssohn would likely not have entertained. In the third dialogue, he writes that

in the realm of truth there is no doubt, no seeming . . . but everything is decidedly true, or decidedly erroneous and false. Everyone will also grant me this, that a doctrine which can only exist if we accept self-contradiction, irresolvable doubts, or undecided uncertainties in the realm of truths, must necessarily be false. (2007: 138)

See Sider (2003) for a relevant discussion of the philosophical issues here.

27. The scholastics contended with variations of this problem. See for discussion Chisholm (1978: Footnote 7), Kretzmann (1976), and Strobach (1998). But none appear to have despaired of an asymmetric analysis, or noted the argument for immortality that arises in the absence of one. See also the related discussion in Hudson (2001: Chapter 4). 
which it does not, matters can either be asymmetric (so that the soul either exists at this point, or doesn't exist, but not both) or symmetric (so that the soul neither exists nor doesn't exist, or both exists and doesn't exist). But the PMSR entails that any asymmetry must be rationally explicable: why would the soul exist at this point of time, rather than fail to exist at it? Insofar as no such rational explanation is available (a matter we revisit below), matters must be symmetrical. The symmetric options are (a) that the soul neither exists nor fails to exist at this point of time, or (b) that the soul both exists and does not exist at this point of time. (a) is not an option, assuming that there are determinate facts of the matter about the existence of a simple soul at a moment (a substantive assumption we revisit below). But neither is (b) an option, since we are supposing that there is a single boundary point between the period of time during which the soul exists and the period during which it does not. So to assert (b) is to assert that it is both the case that the soul exists at this moment, and also not the case that the soul exists at this moment: a direct contradiction. All of this could be avoided if there could be a last moment of existence followed immediately by a first moment of non-existence. But the continuity of time rules this out.

So here, in the Arbitrary Mereotopology Argument, we have an argument that plugs the threatening loophole that the possibility of elanguescence might seem to raise for premise two. Mendelssohn does not explicitly endorse this loophole-plugging argument (or the PMSR), but it follows from claims he accepts (i.e., the PSR). Again, officially, our claim is that Mendelssohn has the materials to argue in this way, even if Bennett, Sassen and others are correct that he does not in fact do so. But it is noteworthy that the hypothesis that he implicitly endorses this argument requires only that he made connections that he was in a position to make. Moreover, this hypothesis resolves the interpretive puzzle that we consider above, by showing how Mendelssohn may have meant to handle the case in question, and it further explains why Mendelssohn places the emphasis he does on the prospect of a last moment of existence followed by a first moment of non-existence.

It may be helpful to compare the question about the boundary point of a soul's going out of being with questions about the position and velocity of the arrow as it comes to rest. First, consider the analogous question about the position of the arrow (assuming for simplicity that the arrow is point-sized): when the arrow arrives at its resting point $r$, is there a first moment when it is located at $r$, or a last moment when it is not located at $r$ ? Assuming the continuity of the arrow's motion, there must be a first moment at which the arrow is located at $r$, for were there a last moment at which it is not located at $r$, then at that moment it would be located some finite distance $\varepsilon$ away from $r$, but there would be no intermediate moment at which its location was a distance $x$ away from $r$ such that $0<x<\varepsilon$, violating continuity. What about the motion of the arrow? Is this 
first moment at which the arrow is located at $r$ the first moment at which the arrow is no longer in motion, or the last moment at which the arrow is in motion? This question is harder to answer, insofar as it hinges to some degree on our analysis of motion. But various options are available in the case of coming to rest that are not available in the case of going out of existence. ${ }^{28}$ For example, one may adopt what Kretzmann (1976) calls the "neutral-instant" analysis, according to which the limiting moment is neither a moment of motion nor a moment of rest. Similarly one might hold that there is no fact of the matter. On one way of developing this view, something is a determinate case of "in motion" only if its rate of change of position is non-zero evaluated in both the past and the future directions of time. Alternatively, we might hold that something is in motion provided that its rate of change of position is non-zero evaluated in at least one temporal direction, or conversely, that something is determinately not in motion unless its rate of change of position is positive in both temporal directions. But no analogue of any of these options is available in the case of coming into or going out of being. ${ }^{29}$

It may also be helpful to compare the question about the boundary point of the soul's going out of being with the puzzle of contact - that is, the puzzle of the mereotopology of spatial boundaries. Consider two objects adjacent in space, for example, the atmosphere and the water. Leonardo da Vinci argues that there is

a common boundary, which is neither air nor water but is without substance, because a body interposed between two bodies prevents their contact, and this does not happen in water with air. (1938/1958: 75-76)30

Against this, Bernard Bolzano (1851: Section 66) argues that exactly one of the water, or the air, must contain the boundary, since otherwise contact between the two would be impossible. Franz Brentano (1976) calls Bolzano's view a "monstrous doctrine" precisely because of the arbitrariness it engenders: which one contains the boundary? ${ }^{31}$ Brentano reasons that to avoid the arbitrariness, a symmetric solution is called for, and he concludes that there are two distinct boundaries (though he takes them to be colocated, and invokes the doctrine of partial plerosis to distin-

28. For a history of the problem see Strobach (1998).

29. Would this disanalogy have been clear to Mendelssohn? An affirmative answer is suggested by Mendelssohn's remarks on the coherence of the succession of changes with the succession of time, e.g.,

The succession of the changes coheres with the succession of time, and is therefore so constant, so indivisible, that one can specify no states which are closest to one another, or between which one could not find a place of transition. (2007: 92)

30. Here and below, we draw on the helpful discussion in Varzi (1997).

31. Brentano (1976: 146). 
guish them). ${ }^{32}$ Recently, Achille Varzi (1997) has suggested that we distinguish between bona fide and fiat boundaries, 33 treating the former a la Bolzano but the latter a la Brentano. For reasons noted above, the da Vincian and Brentanian approaches are non-starters in the temporal existence case: there is no option of saying that at the moment limiting the simple soul's existence, the soul neither exists nor fails to exist, and also no option of saying that, at the limiting moment, it both exists and also does not exist. ${ }^{34}$ What is most telling, for our purposes, is that the Bolzanian approach - which parallels the approach that the proponent of the possibility of the simple soul's disappearance must take-seems to conflict with the PMSR, and it is effectively for this reason that Brentano and others reject it.

In light of all of this, how might proponents of the impermanence of the soul respond? One response to the challenge is to follow Bolzano in rejecting the Principle of Mereotopological Sufficient Reason. Kant might seem to have special reason to do so, since for him the principle would almost certainly count as being synthetic a priori, and Kant's suspicion of synthetic a priori metaphysical principles is well-known. 35

But the fact that some people would reject the PMSR might not trouble Mendelssohn, whose adherence to a full-strength version of the PSR we have noted. Moreover, we expect that many will concur with Brentano and Varzi that the principle is intuitively plausible, at least if it is modestly understood as a methodological maxim that arbitrariness is to be avoided where possible. So it is worth investigating whether the Mendelssohnian challenge can be answered without rejecting the principle. In fact, Kant may have the tools at his disposal to give such an answer.

In the next section, we investigate the possibility that Kant's appeal to elanguescence provides him with the resources to answer this challenge without rejecting the PMSR. More specifically, we consider whether an appeal to elanguescence gives sufficient reason for thinking that a simple would not exist at the terminal boundary point of its existence.

32. See for discussion Smith (1997). See also Chisholm (1983). Incidentally, Chisholm calls Kant's theory of elanguescence a "monstrous hypothesis" (1978: 19). Hic sunt leones.

33. See also Smith (1997).

34. Note that one need not reject the PMSR to follow Bolzano, at least in some cases. As Varzi (1997: Section 7) suggests, holes plausibly do not contain their boundaries while solid objects plausibly do contain theirs. The hardest cases may be those in which there is no qualitative division between the two entities sharing the boundary, but in such cases the Bolzanian approach is less compelling.

35. Kant claims to offer a proof of the general Principle of Sufficient Reason in the Critique (A200-201/B245-246), but closer examination shows he is endorsing only a restricted form of that principle (see Longuenesse 2005: 117-142). Kant's restricted form applies within space and time, however, so it is not obvious what grounds he would have for rejecting a temporal ontological application of the PMSR. Of course, if the soul exists outside of time (as Kant himself arguably holds), then this challenge might be avoided altogether. 
Before doing so, however, there is another important possibility to consider, namely, the possibility that there can be no facts of the matter about what exists or does not exist at an instantaneous moment of no temporal duration.

The clearest case for this conclusion begins with the premise that time is "gunky" - that is, that there are no such things as instantaneous moments of no temporal duration. This "gunky" view, tracing back at least as far as Whitehead (1929), faces many difficult questions (see Varzi 1997: Sections 4-5 on "boundaryfree" theories; and Russell 2008), though it does have contemporary champions (e.g., Zimmerman 1996; Arntzenius 2012).

Such a position might be held in conjunction with the view that continua cannot be composed out of indivisible, extensionless points (such as boundary points), or the related view that continua cannot have extensionless points as parts - views endorsed by Parmenides, Zeno, Aristotle, Duns Scotus, Descartes, Leibniz and Brentano, among many others (Bell 2013). And there is a case that both Kant and Mendelssohn sympathized with thoughts along these lines. For Kant, we see this in light of his understanding of moments as limits which are not components of time (illustrated in the A169-170/B211 passage quoted earlier). And Mendelssohn remarks, "that which is continuous and unified is divided into particular and separate parts only in the imagination and through the separation of the senses" (2007: 94)..$^{36}$

Crucially for our purposes however, even if instantaneous moments are somehow derivative or ideal, and the temporal continuum is not composed out of them, still, provided that they exist, there plausibly are facts about the determinations of things at them. For example, we might deny that a curve is really composed out of infinitesimal tangent lines, but still hold that the direction of the tangent line to the curve is well-defined at each point. And we may accordingly deny that what it is to exist over some continuous span of time just is to exist at each instant within that span, but still hold that there is a fact of the matter about existence at each instant within that span. This appears to have been Leibniz' view. ${ }^{37}$ Where do Kant and Mendelssohn stand?

Kant certainly believed that meaningful questions can be asked about the

36. We find this (Parmenidean) remark puzzling. Does Mendelssohn mean to suggest that any division of a continuum into parts is ideal? But even if this remark should be regarded as hyperbolic, we also have contextual evidence that Mendelssohn may have held anti-atomist sympathies. As an anonymous reviewer pointed out to us, both Mendelssohn and Kant would have been familiar with Bayle's discussion of Zeno (in particular, Note [G]) in the Dictionnaire Historique et Critique, another source for this doctrine (see Bayle 1734: 610-614). In Mendelssohn's case, it may also be warranted to assume a default sympathy for Leibniz's view on the matter, on which see the following note.

37. "Nothing of time does ever exist, but instants; and an instant is not even itself a part of time. Whoever considers these observations will easily apprehend that time can only be an ideal thing" (Leibniz 1989: 340). 
status of a quality at a boundary point. We can see this in his distinction between extensive and intensive magnitudes, where the latter are defined in terms of having qualities or reality at an instant:

Apprehension, merely by means of sensation, fills only an instant ... As something in the appearance, the apprehension of which is not a successive synthesis, proceeding from the parts to the whole representation, it therefore has no extensive magnitude; the absence of sensation in the same moment would represent this as empty, thus $=0$. Now that in the empirical intuition which corresponds to the sensation is reality ... [and] that which corresponds to its absence is negation $=0 \ldots$ [E]very reality in the appearance has intensive magnitude, i.e., a degree. If one regards this reality as cause (whether of the sensation or of another reality in appearance, e.g., an alteration), then one calls the degree of reality as cause a "moment," e.g., the moment of gravity, because, indeed, the degree designates only that magnitude the apprehension of which is not successive but instantaneous. (A167-169/B209-210)

Moreover, recall that as Kant summarizes Mendelssohn's master argument, it hinges on the idea that "there would be no time at all between a moment in which it is and another moment in which it is not, which is impossible" (B414). So even if Kant ultimately has misgivings on this score, he appears to have intended not to rely on them in replying to Mendelssohn. Kant therefore cannot, or anyway does not, avoid the challenge posed by PMSR by denying that there are facts about the status of qualities at instantaneous moments, or boundary points, of time.

Of course, if Mendelssohn himself denied there were such facts, he could not endorse the Arbitrary Mereotopology Argument that we are here offering on his behalf. But the text of the Phädon suggests that Mendelssohn does think we can speak sensibly about existence at a moment. He says, for example, "all changeable things cannot remain unchanged even for a moment" (2007:90) and "what is changeable doesn't exist for a moment without being actually changed" (2007: 92)..$^{38}$

38. In passing, we note one further intriguing possibility suggested by these passages. Mendelssohn might be read here as saying that change takes place even within a single moment. On one construal of such a view, change between states is more fundamental than states themselves. This might suggest a new strategy of response to our mereotopological argument: hold that what exists at the transitional moment is the transitional state of affairs, s's-going-from-being-to-non-being. But is the existence of this state of affairs compatible with the existence of $S$ ? Is it compatible with the non-existence of S? If it rules out one but not the other then the asymmetry remains. Alternatively, one might deploy Brentano's conception of half-plerosis here to argue that the state of affairs of the soul's existence and the state of affairs of its non-existence both exist in partial plerosis 


\section{Elanguescence and Arbitrary Boundaries}

We turn our attention now to the question of whether Kant's appeal to elanguescence might help settle whether the soul exists or does not exist at the terminal boundary point of its existence. As before, we do not claim that Kant himself meant to address the mereotopological issue, though we also do not see any evidence that rules this out.

To begin, we identify supporting principles which entail that the boundary moment is a first moment of non-existence, rather than a final moment of existence. Suppose that we may speak sensibly of the amount of power that a thing has, where a thing that does not exist has 0 power. ${ }^{39}$ Then suppose we make the two following further assumptions:

Power Density: Where $x$ and $y$ are finite, non-negative amounts of power, if a simple's power at one time is $\mathrm{x}$ and at a later time is $\mathrm{y}$, then at some intermediate time, that simple's power is strictly intermediate between $x$ and $\mathrm{y}$.

Reserved Power: For a thing to exist at a time it must have some finite, positive amount of power at that time.

From these we may conclude that there can never be a last moment of a simple's existence, and so (given that the process is continuous in time) there must be instead a first moment of its non-existence. Suppose for reductio that $t_{1}$ is a simple's last moment of existence. Then by Reserved Power, at $t_{1}$ the simple has some finite, positive amount of power $x \neq 0$. Say that $t_{3}$ is a later moment at which the simple no longer exists and so has 0 power. But then by Power Density, there is a moment $t_{2}$ between $t_{1}$ and $t_{3}$ at which the simple has an amount of power $z$ strictly intermediate between $x$ and 0 . But then $z$ must be strictly greater than 0 , and so it must be positive. But if a simple has non-zero, positive power at $t_{2}$ the simple exists at $t_{2}$, and so $t_{1}$ is not the last moment of its existence.

Might Kant's conception of elanguescence involve Power Density and Reserved Power? If so, then he may have an answer to the Mendelssohnian Arbitrary Mereotopology Argument after all.

at the relevant moment. But this is in effect to hold that there can be ontic vagueness of existence, a possibility that a rationalist like Mendelssohn likely would have rejected (see above, Footnote 26) but that admittedly merits consideration. Our thanks to Barry Smith for discussion on this point.

39. Strictly, what is required is that there is a continuous measure on the set of possible power configurations that a thing can have at a time: a function mapping each individual power configuration to some element in a continuously valued linearly ordered set with a least element corresponding to the null state of having no power at all (presumably, the real numbers greater than or equal to zero). For a relevant discussion of measure theory see Folland (2007). 
Kant's theory of intensive magnitude, insofar as it illustrates his more general theory of power, may appear to support these assumptions. For Kant, a thing's power can be understood as its degree of reality, where (as the above quote shows) this is sometimes understood in terms of the gradation of apprehension: the fact that our empirical consciousness of a thing can vary gradually in intensity (A166-B208). Assuming that this structure would carry over to the case of the soul, then, we are warranted in thinking of gradual variation in power in terms of (linearly ordered) amounts.

This gives us some of what is required: it motivates the thought that if a thing no longer exists at a time $t$, then it will have no power at that time. It also motivates the thought that if a thing has some positive amount of power (e.g., it impresses upon our empirical consciousness to some non-zero degree) then it does still exist.

Strictly speaking, this does not yet imply Power Density, because it is one thing to say that a quantity can be measured in degrees and another to say that its dynamics are continuous in terms of those degrees. However, it is dialectically acceptable for Kant to assume a principle of the continuity of change, since, as we noted above, Mendelssohn clearly accepts one: "everything changeable must be in a continuous process of change" (2007: 108). Kant's discussions of the question involve some subtleties (compare A171-B213 with A207-209/B252-254), but he does seem to accept the view overall..$^{\circ}$ So Kant appears to be entitled to appeal to Power Density, and perhaps we can read his invocation of elanguescence as making such an appeal. If he were also entitled to appeal to Reserved Power, then he would have an answer to the Arbitrary Mereotopology Argument.

\section{Power and Existence}

Unfortunately for Kant, there are two obstacles to justifying Reserved Power. First, according to standard measure theory, there is a difference between a volume's having measure zero and that volume's taking up no space at all. If a volume in a continuous space (like Euclidean space) consists of a single point, or a countable collection of points, or indeed a continuous collection of points of lower dimension than the ambient space, then it has measure zero. ${ }^{41}$ But just as we should eschew a principle saying that only things of positive (i.e., non-zero)

40. See for discussion Powell (1990: 116). Powell seems to overlook the fact that Kant's doctrine of the continuity of time (between every two moments there is an intermediate moment) does not imply that all changes in time are continuous (that between any two states there is a state of intermediate quality).

41. Such sets may also be unmeasurable, if they are not suitably well behaved. See again Folland (2007). 
spatial measure can exist (insofar as we allow that point-sized simples may also exist) so too we should eschew a principle saying that only things of positive (i.e., non-zero) power measure can exist, because we have no reason to deny that things having only "an infinitesimal amount" of power can exist. ${ }^{2}$

Second, there is no clear reason to deny that a thing might exist (for a very short time, i.e., a single moment) while having no power at all-that is, that a thing can momentarily run on empty. Of course, if a thing does not exist at some time $t$, then it has no power at that time. The converse is not obvious, however. Why not allow, in particular, that a thing exists at one final moment, without any power at all, provided that that moment is the boundary of a period during which that thing's power gradually decreases to zero?43

Now, there is a case that Mendelssohn's own remarks on this matter support Reserved Power. If so, then the above reasons would not prevent Kant from appealing to the principle. Consider again the passage: "Shall all [the soul's] sensations, its imaginations, its desires and aversions, appetites and passions vanish, and leave behind not the slightest trace? . . Impossible, said Cebes. What would this be other than a total annihilation" (Mendelssohn 2007: 97-98). Similarly, in his appendix to the third addition, Mendelssohn indicates that "the power to think and will, or the powers to think and will, can never be annihilated by natural changes" (2007: 150).

However, neither of these remarks strictly entails Reserved Power, since Mendelssohn does not specify what such a naturally impossible annihilation would entail. Moreover, in other passages, Mendelssohn appears to allow that souls can momentarily exist without power (or action or suffering):

Sleep, fainting, dizziness, ecstasies, and a thousand other experiences teach us that a total deprivation of all consciousness, of all awareness of one's senses, would not be totally impossible, at least for a short time. (2007: 126)

Thought can be entirely inactive for a long time in a sleeping person ... But then the original power, from which these capabilities are merely derivations . . . is nothing less than inactive. (2007: 148-149) ${ }^{44}$

42. While Mendelssohn as a Leibnizian would have no difficulty with the notion of an infinitesimal amount of power, all that is required here is that we may think of the measure of power configurations as consisting of point-set theoretic continua of some kind, i.e., sets of uncountably many "points" of power. This is tenable on Kant's conception of intensive magnitude since, for example, we may understand intensity in terms of some kind of field of sensation, and then formally understand that field in terms of points. We stress here that our aim is to show what must be ruled out to settle the matter, not to establish that such a conception of powers is correct.

43. For a relevant discussion, see Chepurin (2010).

44. Mendelssohn also notes that he believes thought is a fundamental power of the soul (2007, 149). The context of this latter passage, however, raises some questions about its interpretation. 
Mendelssohn's point here is at least prima facie plausible: it certainly seems that our minds can be entirely inactive for at least short periods.

Thus, even granting Kant his idiosyncratic theory of degrees of reality and the possibility of elanguescence, we lack a sufficient reason to accept Reserved Power, and so to take it that the boundary moment is a first moment of nonexistence rather than a last moment of existence.

Does the argument we have described prove too much? Consider any property $\mathrm{P}$ that something may change from having to not having. Say that $t_{1}$ marks the boundary between the period when the thing instantiates $P$ and the period when it does not. We can then ask: does the thing instantiate $\mathrm{P}$ at $\mathrm{t}_{1}$, or not? If any answer would be arbitrary, do Mendelssohnian principles suggest that change in $\mathrm{P}$ is impossible? And does this prove too much?

In reply, we accept that the reasoning we have offered on Mendelssohn's behalf (i.e., the Arbitrary Mereotopology Argument) indeed suggests that change is impossible provided that any answer to the question of what transpires at the boundary would be arbitrary. However, we maintain that this does not prove too much. For we have not argued here against the general availability of non-arbitrary answers to mereotopological questions. In some cases, like that of a body going from life to death, a non-arbitrary symmetric account is available, because there can be a span of time during which the body is neither determinately dead nor determinately alive. In other cases, like the case of the arrow coming to be located at (resting) point $\mathrm{r}$, a non-arbitrary asymmetric account is available (as we discuss in Section 2): there, basic kinematics settles that there is a first moment at which the arrow is located at that point, rather than a last moment at which it is located elsewhere. 45 And we have just seen that a defense of both Power Density and Reserved Power would settle the case of elanguescence. We now turn to a discussion of some arguments from contemporary metaphysics that are analogous to the Mendelssohnian Arbitrary Mereotopology Argument.

There is a case to be made that Mendelssohn, as a Leibnizian, in fact meant to say that the original powers must indeed be active, though differently applied (a point Leibniz argues against Locke in the New Essays). But this is speculative. Our claim is that Mendelssohn does not clearly commit himself to Reserved Power.

45. Another worry about proving too much comes from the principle of continuity itself, since many take it to be a live empirical prospect that there is discontinuity in nature-e.g., that time itself is discrete. But as we suggest above, one reading of the principle of continuity takes it to affirm that insofar as the succession of time is continuous, so too the succession of changes of state must also be continuous. So construed, Mendelssohn's premise that time is continuous is an empirical premise, and if it is false, his argument must be restricted accordingly. 


\section{Mendelssohn Lives On: Lewis, Sider, and Unger}

Since we believe that Mendelssohn's master argument supplemented with the PMSR has philosophical merit and contemporary relevance, it is worth spending a little more time considering the connections between this historical exchange between Kant and Mendelssohn and some recent arguments in the metaphysical literature. David Lewis and Ted Sider both appeal to the non-vagueness of existence, and a distaste for arbitrariness, to establish global metaphysical conclusions about what things there are. Peter Unger appeals to similar considerations to establish the immateriality of the soul. Notably, none of these more recent authors explicitly endorses the general Principle of Sufficient Reason, yet as we will see, each endorses an anti-arbitrariness principle along the lines of the PMSR.

Lewis (1986: 212), for example, argues that composition must be universal, because otherwise, since it cannot be vague whether a given precisely specified set of things has a fusion, any cut-off point would be arbitrary. Even closer to our topic, Sider $(1997,2001)$ argues that every region of spacetime must be the exact lifespan of a material individual, because otherwise, since it cannot be vague whether a given precisely specified region of spacetime is the exact lifespan of a material individual, any cut-off point (between those regions that are exact lifespans of material individuals and those that are not) would be arbitrary. ${ }^{6}$

Peter Unger (2005) advances an argument for substance dualism that appeals to considerations of arbitrariness that are similar to those Mendelssohn considers and to those which stand behind the PMSR.47 Unger's argument turns on the problem of the many minds: the problem of saying precisely which physical system is the body of an experiencer, given that for any candidate there are legions of other almost entirely overlapping candidates. Unger argues that we cannot say that all these physical systems are minds, ${ }^{48}$ and he also argues that, because it would be unacceptably arbitrary for any one but not the others to be a mind, we must instead hold that none are minds, and instead, the mind is something

46. This is a simplified presentation. Strictly speaking, Sider does not appeal to regions of spacetime, but instead to "minimal d-fusions of assignments", where an assignment is a function that specifies, for each of some set of times, a class of objects existing at that time, and a minimal $\mathrm{d}$-fusion of an assignment $f$ is an entity that has, for any time $\mathrm{t}$ in the domain of the assignment $f$, precisely the objects in the class $f(t)$, and does not have any parts at any times not in the domain of $f$. Sider then notes that if some assignments have minimal d-fusions while others do not, there would be a "continuous series" between assignments that do and assignments that do not have minimal d-fusions, with an (unacceptably) "abrupt cut-off" somewhere in the series. There is a striking parallel here with Mendelssohn's appeal to the principle of continuity discussed above, but we note that as Sider uses it "continuous" is idiosyncratic, and can describe a discrete series of cases provided that each is relevantly qualitatively similar to the next (Sider 1997: Sections 3.2-3.3; 2001: Chapter 4).

47. Zimmerman (2011) deploys a related argument.

48. See Hudson (2001: Chapter 1) for a related argument. 
immaterial. Notably, while Unger (2005: Chapter 8) considers the possibility that immaterial minds are immortal, he holds that, provided entities may exist with the propensity to annihilate them, the (sudden) annihilation of souls is possible. Present considerations may put pressure on a view like Unger's to say precisely which forms of arbitrariness are acceptable and which are not.

It is also worth considering ways that the Arbitrary Mereotopology Argument generalizes. As we emphasize above, generalizations may be harder to find than it first appears. Relevant cases must preclude symmetric solution-among other things, they must not admit of vagueness - and they must also preclude non-arbitrary asymmetric solution, of the sort that the equations of motion seem to offer in the case of the arrow coming to rest.

But one case worth considering in this context is the question of whether something can cease to be phenomenally conscious (considered independently of the question of whether that something is a simple soul). Some philosophers have recently argued that terms like "phenomenally conscious" are not vague: experiences may come in different grades of intensity, but an experience of any non-zero degree is an experience, full stop. ${ }^{49} \mathrm{But}$ it is also hard to see how anything like kinematics might settle the boundary question, at least if materialism is true. ${ }^{50}$ Consciousness may indeed fade in intensity, but for reasons parallel to those considered in Section 4, it does not follow that there is a first moment of unconsciousness rather than a last moment of consciousness. Therefore, there may be a defensible Mendelssohnian argument for the claim that consciousness never ceases, at least if materialism is true.

For some, this may just underscore that PMSR must be false, or that spacetime must be gunky after all without there being facts about how things are at limits. But as we have seen, Mendelssohn and Kant are not alone in appreciating the cost of such measures. Kant may not have found an easy reply to Mendelssohn, but there are formidable questions here for contemporary authors as well.

\section{Acknowledgments}

For helpful discussions and feedback, we are grateful to Mike Raven and Barry Smith. We would also like to thank two anonymous Ergo referees for their thoughtful and challenging comments, and the editorial team at Ergo.

49. See for example Antony (2008), Sebastian (2011), Simon (2017).

50. If materialism is false, then we know very little about the underlying kinematics (of immaterial mental processes), and so cannot rule out that these kinematics settle the issue. Note that Mendelssohn's Arbitrary Timing Argument would be more compelling were materialism his target: it is clear enough that nothing in the physical kinematics settles the exact time of annihilation. 


\section{References}

Allison, Henry (2004). Kant's Transcendental Idealism (2nd ed.). Yale University Press.

Ameriks, Karl (2000). Kant's Theory of Mind (2nd ed.). Oxford University Press. https:// doi.org/10.1093/0198238975.001.0001

Antony, Michael (2008). Are Our Concepts conscious state and conscious Creature Vague? Erkenntnis, 68(2), 239-263. https://doi.org/10.1007/s10670-007-9061-2

Arntzenius, Frank (2012). Space, Time and Stuff. Oxford University Press. https://doi. org/10.1093/acprof:0so/9780199696604.001.0001

Bayle, Pierre (1734). The Dictionary Historical and Critical of Mr Peter Bayle (2nd ed., P. Des Maizeaux, Trans.). Knapton et al.

Bell, John L. (2013). Continuity and Infinitesimals. In Edward N. Zalta (Ed.), The Stanford Encyclopedia of Philosophy (Summer 2017 Edition). Retrieved from https://plato.stanford.edu/archives/sum2017/entries/continuity/

Bennett, Jonathan (1974). Kant's Dialectic. Cambridge University Press.

Bolzano, Bernard (1851). Paradoxien des Unendlichen (F. Prihonsky, Ed.). Reclam.

Bolzano, Bernard (1950). Paradoxes of the Infinite (D. A. Steele, Ed.). Routledge \& Kegan Paul.

Brentano, Franz (1976). Philosophische Untersuchungen zu Raum, Zeit und Kontinuum (S. Körner and R. M. Chisholm, Eds.). Meiner.

Brentano, Franz (1988). Philosophical Investigations on Space, Time and the Continuum (B. Smith, Trans.). Croom Helm.

Brook, Andrew (1994). Kant and the Mind. Cambridge University Press. https://doi. org/10.1017/CBO9780511624629

Cajori, Florian (1923). Grafting of the Theory of Limits on the Calculus of Leibniz. The American Mathematical Monthly, 30(5), 223-234. https://doi.org/10.2307/2299086

Chepurin, Kirill (2010). Kant on the Soul's Intensity. Kant Yearbook, 2, 75-94.

Chisholm, Roderick (1978). Coming to Be and Passing Away: Can the Metaphysician Help? In John Donnelly (Ed.), Language, Metaphysics, and Death (13-24). Fordham University Press.

Chisholm, Roderick (1983). Boundaries as Dependent Particulars. Grazer Philosophische Studien, 20(1), 87-95. https://doi.org/10.5840/gps1983206

Chisholm, Roderick (1991). On the Simplicity of the Soul. Philosophical Perspectives, 5, 167-181. https://doi.org/10.2307/2214094

da Vinci, Leonardo (1958). The Notebooks of Leonardo da Vinci (E. MacCurdy, Trans. and Ed.). G. Braziller. (Original work published 1938)

Dyck, Corey (2014). Kant and Rational Psychology. Oxford University Press. https://doi. org/10.1093/acprof:0so/9780199688296.001.0001

Falkenstein, Lorne (1998). A Double Edged Sword? Kant's Refutation of Mendelssohn's Proof of the Immortality of the Soul and its Implications for his Theory of Matter. Studies in the History of Philosophy of Science, 29(4), 561-588. https://doi.org/10.1016/ So039-3681(98)00022-3

Feynman, Richard, Robert Leighton, and Matthew Sands (2015). The Feynman Lectures on Physics (Vol. II). Basic Books.

Folland, Gerald (2007). Real Analysis: Modern Techniques and their Applications. Wiley.

Grier, Michelle (2001). Kant's Doctrine of Transcendental Illusion. Cambridge University Press. https://doi.org/10.1017/CBO9780511498145 
Hudson, H. (2001). A Materialist Metaphysics of the Human Person. Cornell University Press.

Kabitz W. (1913). Über eine in Gotha aufgefundene Abschrift des von S. König in seinem Streite mit Maupertuis und der Akademie veröffentlichten, seinerzeit für unecht erklärten Leibnizbriefes. Sitzungsberichte der Königlich Preussischen Akademie der Wissenschaften, 2, 632-638.

Kant, Immanuel (1997). Lectures on Metaphysics (Karl Ameriks and Steve Naragon, Eds. and Trans.). Cambridge University Press. https://doi.org/10.1017/CBO9781107049505

Kant, Immanuel (1997). Critique of Pure Reason (Paul Guyer and Allen Wood, Trans.). Cambridge University Press.

Kant, Immanuel (2001). Prolegomena to Any Future Metaphysics (Gary Hatfield, Trans.). Cambridge University Press.

Kitcher, Patricia (2011). Kant's Thinker. Oxford University Press. https://doi.org/10.1093/ acprof:0so/9780199754823.001.0001

Klemme, Heiner (1995). Kants Philosophie des Subjekts. Felix Meiner Verlag.

Kretzmann, Norman (1976). Incipit/Desinit. In Paul K. Machamer and Robert G. Turnbull (Eds.), Motion and Time, Space and Matter (101-136). The Ohio State University Press.

Leibniz, Gottfried (1963). Mathematische Schriften (7 Vols.) C. I. Gerhardt (Ed.). Georg Olms.

Leibniz, Gottfried (1969). Philosophical Papers and Letters (2nd ed., Leroy E. Loemker, Ed. and Trans.). Reidel.

Leibniz, Gottfried (1989). Philosophical Essays (Roger Ariew and Daniel Garber, Ed. and Trans.). Hackett.

Leibniz, Gottfried (1996). New Essays on Human Understanding (Peter Remnant and Jonathan Bennett, Trans.). Cambridge University Press. https://doi.org/10.1017/ CBO9781139166874

Lewis, David (1986). On the Plurality of Worlds. Blackwell.

Longuenesse, Béatrice (2005). Kant on the Human Standpoint. Cambridge University Press. https://doi.org/10.1017/CBO9780511487279

Markosian, Ned (1998). Simples. Australasian Journal of Philosophy, 76(2), 213-226. https:// doi.org/10.1080/00048409812348361

Mendelssohn, Moses (2007). Phädon: or, On the Immortality of the Soul (Patricia Noble, Trans.). Peter Lang.

Mendelssohn, Moses (1997). Philosophical Writings (Daniel O. Dahlstrom, Trans.). Cambridge University Press. https://doi.org/10.1017/CBO9781139164078

Mendelssohn, Moses (1972). Gesammelte Schriften, Jubiläumsausgabe der Akademie für die

Wissenschaft des Judentums (Vol. 3.1). F. Bamberger and Leo Strauss (Eds). Frommann. (Facsimile edition)

Mijuskovic, B. (1974). The Achilles of Rationalist Arguments. Martinus Nijhoff. https://doi. org/10.1007/978-94-010-2037-4

Pelczar, Michael (2015). Sensorama: A Phenomenalist Analysis of Spacetime and its Contents. Oxford University Press. https://doi.org/10.1093/acprof:oso/9780198732655.001.0001

Powell, C. Thomas (1990). Kant's Theory of Self-Consciousness. Clarendon Press. https:// doi.org/10.1093/acprof:0so/9780198244486.001.0001

Russell, Bertrand (1914). The World of Physics and the World of Sense. In Our Knowledge of the External World (106-134). George Allen \& Unwin. 
Russell, Jeff (2008). The Structure of Gunk: Adventures in the Ontology of Space. In Dean Zimmerman (Ed.) Oxford Studies in Metaphysics (Vol. 4, 248-274). Oxford University Press.

Sassen, Brigitte (2008). Kant and Mendelssohn on the Implications of the 'I Think'. In Thomas Lennon and Robert Stainton (Eds.), The Achilles of Rationalist Psychology (215-233). Spinger. https://doi.org/10.1007/978-1-4020-6893-5_12

Sebastian, Miguel (2011). Self Involving Representationalism: A Naturalistic Theory of Phenomenal Consciousness (Doctoral Dissertation). Retrieved from http://www.tesisenred.net/handle/10803/32012

Shavin, D. (2007). Introduction to Mendelssohn's Phädon. In Mendelssohn, Moses, Phädon: or, On the Immortality of the Soul (Patricia Noble, Trans.). Peter Lang.

Shavin, D. (1999). Philosophical Vignettes from the Political Life of Moses Mendelssohn. FIDELIO Magazine, 8(2), 29-46.

Sider, Theodore (1997). Four-Dimensionalism. Philosophical Review, 106(2), 197-231. https://doi.org/10.2307/2998357

Sider, Theodore (2001). Four-Dimensionalism. Oxford University Press. https://doi. org/10.1093/019924443X.001.0001

Sider, Theodore (2003). Against Vague Existence. Philosophical Studies, 114(1-2), 135-146.

Sider, Theodore (2013). Against Parthood. In Karen Bennet and Dean Zimmerman (Eds.), Oxford Studies in Metaphysics (Vol. 8, 237-293). https://doi.org/10.1093/acprof: oso/9780199682904.003.0006

Simon, Jonathan (2017). Vagueness and Zombies: Why 'Phenomenally Conscious' Has No Borderline Cases. Philosophical Studies, 174(8), 2105-2123. https://doi.org/10.1007/ S11098-016-0790-4

Smith, Barry (1997). Boundaries: An Essay in Mereotopology. In L. H. Hahn (Ed.), The Philosophy of Roderick Chisholm (534-561). Open Court.

Strauss, Leo (1972). Introductory Remarks. In Moses Mendelssohn, Gesammelte Schriften, Jubiläumsausgabe der Akademie für die Wissenschaft des Judentums (Vol. 3.1). F. Bamberger and Leo Strauss (Eds). Frommann. (Facsimile edition)

Strobach, N. (1998). The Moment of Change: A Systematic History in the Philosophy of Space and Time. Springer-Science+Business Media. https://doi.org/10.1007/978-94-0159127-0

Tomasoni, Francesco (2011). Mendelssohn's Concept of the Human Soul in Comparison with Those of Georg Friedrich Meier and Kant. In Reinier Munk (Ed.), Moses Mendelssohn's Metaphysics and Aesthetics (131-155). Springer. https://doi.org/10.1007/97894-007-2451-8_7

Unger, Peter (2005). All the Power in the World. Oxford University Press.

Van Cleve, James (1999). Problems from Kant. Oxford University Press.

Varzi, Achille (1997). Boundaries, Continuity and Contact. Noûs, 31(1), 26-58. https://doi. org/10.1111/0029-4624.00034

Whitehead, Alfred N. (1929). Process and Reality. An Essay in Cosmology. Macmillan.

Wuerth, Julian (2014). Kant on Mind, Action, and Ethics. Oxford University Press. https:// doi.org/10.1093/acprof:0so/9780199587629.001.0001

Zimmerman, Dean (1996). 'Could Extended Objects Be Made Out of Simple Parts? An Argument for 'Atomless Gunk'. Philosophy and Phenomenological Research, 56(1), 1-29. https://doi.org/10.2307/2108463

Zimmerman, Dean (2011). From Experience to Experiencer. In Mark C. Baker and Stewart Goetz (Eds.), The Soul Hypothesis (168-196). Continuum Publishing. 